\title{
Analysis of problems and support for solutions related to phases and critical points in the cycle of reproduction of industrial real estate
}

\author{
Petr Graboviy and Sergei Beliakov* \\ Moscow State University of Civil Engineering, Yaroslavskoe shosse, 26, Moscow, 129337, Russia
}

\begin{abstract}
The process of industrial production is dynamic. It flows in time, undergoing numerous (deliberate and forced) changes. The current rates of scientific and technological progress methodically increasingly require anticipatory long-term forecasts. By selected critical points can be analyzed the general different processes associated with the risk of building the industrial park facilities, although the cycles of reproduction and its individual phases will at the same time have particular differences in magnitude and interpretation. The scientific and methodological basis for the application of program management as an organizational form of managing the construction phase is the implementation of completed construction queues using the nodal method at critical points in the lifecycle of the multiproject, which makes it possible to identify possible options and methods for shortening construction times that become important reserves for increasing the efficiency of operation and reducing costs construction at the expense of costs in total cost of ownership of the real estate of the industrial park.
\end{abstract}

\section{Introduction}

There are two types of industrial parks: an industrial park of the type "greenfield", created on a previously undeveloped land plot, not provided with engineering and transport infrastructure at the time of the project; an industrial park of the "brownfield" type on the basis of the capital reconstructed objects previously intended for a different production function.

The scientific and methodological basis for evaluating the efficiency of construction and operation of industrial real estate is the decomposition of a complex production structure into component parts (technological modules) and the achievement on this basis of an accelerated start-up of commissioning and, accordingly, the commissioning of both individual parts and the industrial park as a whole [1-8].

The application of the decomposition method allows:

- to coordinate the work of all construction participants on each module and industrial park as a whole;

\footnotetext{
* Corresponding author: serj-bel@yandex.ru
} 
- to carry out targeted and interconnected design, preparation of production, organization and management of construction;

- to ensure the maximum combination of construction, erection and special construction works, organize their implementation by specialized streams;

- to focus and use rationally the financial, logistical and labor resources;

- to apply intensive methods of performing construction and installation works, improve the organizational and economic reliability of industrial construction and its effectiveness.

\section{Materials and Methods}

The process of industrial production is dynamic. It flows in time, undergoing numerous (deliberate and forced) changes. The current rates of scientific and technological progress methodically increasingly require anticipatory long-term forecasts $[9,10]$. The period of major structural reorganization in industrial construction is an ecological 10-15 years.

The cycle of joint reproduction of industrial real estate can be divided into phases and critical points (Figure 1).

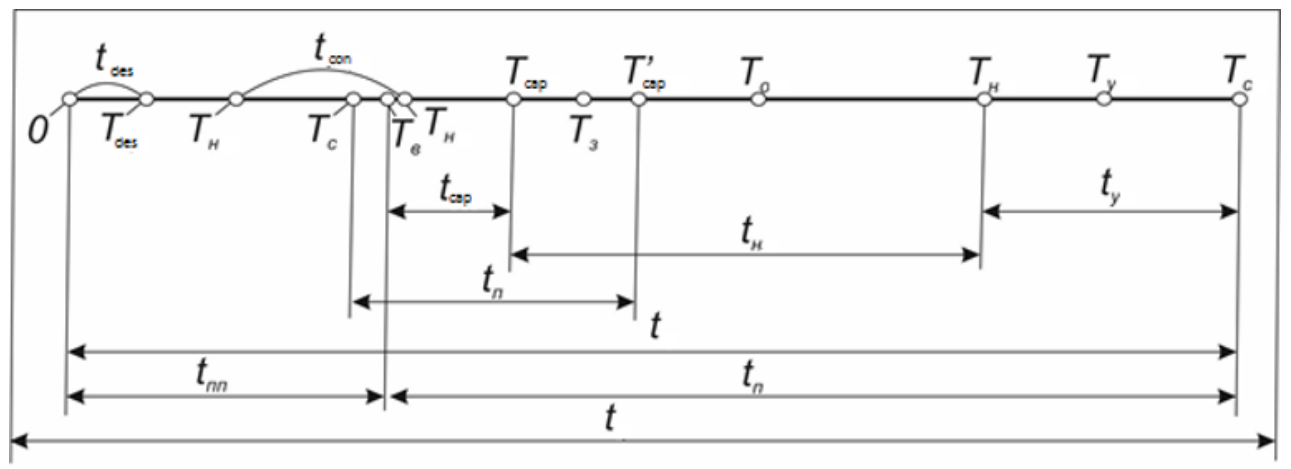

Fig. 1. Phases and critical points of the cycle of reproduction of industrial real estate.

By selected critical points can be analyzed the general different processes associated with the risk of building the industrial park facilities, although the cycles of reproduction and its individual phases will at the same time have particular differences in magnitude and interpretation. Any phase can include the costs not only of working time itself, but also downtime [11].

Evaluation of their effectiveness can only be from the perspective of a long period. Several modifications of special dynamic methods and integral efficiency criteria have been proposed and are being used for constant time [12-14].

The integral criterion for estimating the effectiveness of reproduction should be calculated for a period equal to:

$$
\tau=t_{\text {des }}+t_{\text {cons }}+t_{c a p}+t_{o p}
$$

where $t_{d e s}$, $t_{c o n s}$ and $t_{c a p}$ - the duration of the periods of design, construction and development of industrial park capacity (industry average);

$t_{o p}$ - the duration of the normal operation period, sufficient to assess the efficiency of the industrial property object ( $t_{o p}=t_{p p}$, where $t_{p p}$ is the estimated payback period).

It is easy to see that the evaluation period $\tau$ represents a more objectively calculated modification of the estimated payback period $t_{p p}$. Indicator $\tau$ is the same period taken to 
evaluate the effectiveness of the option as $t_{p p}$, but it reflects the actual sequence of construction phases, mastering the projected results and subsequent normal operation of the object.

Critical points characterize the turning points typical for any stages of the process of reproduction of industrial real estate. They are universal for objects of any nature, but their specific location on the time axis may be different. The location of the critical points gives a clear description of the main features of the economic dynamics of the process under consideration and a conveniently formalized basis for its analysis.

The phases of the life cycle of reproduction, allocated to the test in formula (1), are limited to the following values of the critical points:

$$
\left\{\begin{array}{c}
t_{d e s}=\left[0, T_{\text {des }}\right] \\
t_{\text {op }}=\left[T_{\text {cap }}, T_{\text {cons }}\right] \\
t_{\text {cons }}=\left[0, T_{\text {cons }}\right]
\end{array},\right.
$$

One of the most important categories of the theory of efficiency is usually the order of construction, i.e. the period between the investment of funds and the beginning of the receipt of an effect from them [15].

In the most general form, the main regularities of the economic dynamics of the reproduction processes of the industrial level of the park, taking into account the construction phase, are as follows.

To evaluate the effectiveness of decisions taken, it is necessary to start from integral criteria of the ratio of costs and results for all periods of the personal life cycle of industrial real estate. This can be described in three situations.

First situation: an industrial park is created in a region where there are no building resources for its erection. All resources are supplied to the construction site from the head residential and production base of the general contractor organization. In this case, conditions are created to shorten the terms of commissioning the facility; the level of system mobility increases, which leads to additional work; increases the estimated cost of the object due to the costs of increasing the mobility of the system.

Second situation: an industrial park is created in the region, in which it is planned to create production and social spheres of appropriate capacity. All the work that is part of the life cycle of the system is performed sequentially. In this case, the minimum level of system mobility is reached; the minimum amount of investment in the object and additional investments are required in the production and social spheres of the system. This leads to an increase in the terms of commissioning of the projects of industrial real estate into operation.

Third situation: an industrial park is created in conditions that provide a rational combination of the use of stationary, mobile and regional residential and production bases during the implementation of the investment project.

Determining the ratio of different periods, you can get the comparative effectiveness of the life cycle of the project. On the time axis, diagrams are depicted characterizing the costs and results of the analyzed variants described by the first and second situations (Figure 2), which differ in the level of mobility of the system when constructing identical objects. 


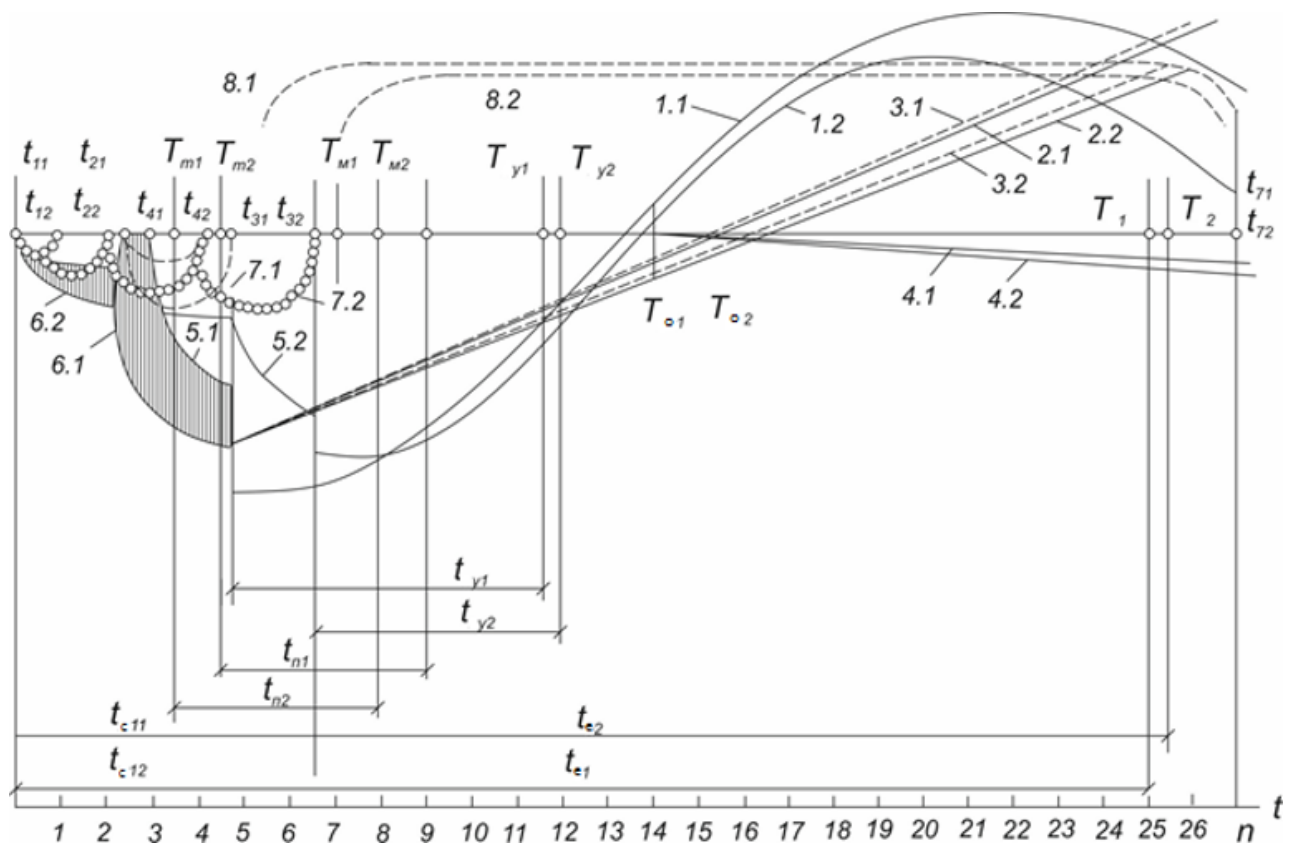

Fig. 2. Graphic modelling of constituent elements and critical points of the life cycle for the reproduction of industrial real estate industrial park in different conditions.

Diagrams of increasing values:

1.1 - characteristics of savings from profit and renovation flows in the first situation;

1.2 - the same for the 2nd situation;

2.1 - normative efficiency of capital investments in the 1 st situation;

2.2 - the same for the 2nd situation;

3.1 - the same taking into account the introduction of innovations in the first situation;

3.2 - the same for the 2nd situation;

4.1 - loss of value under the influence of depreciation in the 1st situation;

4.2 - the same for the 2nd situation;

5.1 - the formation of funds (capital investments) in the first situation;

5.2 - the same for the 2nd situation;

6.1 - an increase in the estimated cost as a basis for the cost of mobility of the system in the first situation;

6.2 - the same at the expense of the cost of designing a residential and production base in the second situation.

Diagrams of annual values:

7.1 - capital investments for the first situation parts;

7.2 - the same for the 2nd situation;

8.1 - output at the first situation;

8.2 - the same for the 2nd situation.

The diagram of accumulation characteristics from the renovation flow and the flow of work in the initial period of project operation in the 1st situation 1.1 has the worst value in the stage in comparison with the second situation 1.2 due to the difference in capital investments. In subsequent periods of operation, the pace of these savings due to different terms change and the nature of curves 1.1 and 1.2 demonstrates the greater efficiency of systems in the 1 st situation compared to the 2 nd. Therefore, in order to evaluate the options under consideration, it is necessary to compare costs and results for all stages of the life 
cycle, that is, preserving the integrity of the life cycle, to commensurate its parameters in dynamics.

To determine the comparative efficiency of construction options, a payback period can be applied. In this case, it is possible to take into account not only their volumes associated with erection, but also the dynamics of savings from profit flows and renovation flows, which ensure a return on investment. It is rational to use the criterion of integral costs.

This criterion is considered as integral, leading all kinds of costs and results to the year of normative recoupment for the situations in question.

At the same time, the procedure of bringing the variants to a comparable type in terms of output volumes and balancing of other types of resources over time becomes more complicated.

The order of bringing the options in a comparable form, taking into account the dynamics of the life cycle of the object and calculating the compensation costs, is as follows:

- for each year, the volume of necessary products is determined for one or another variant of compensation;

- compensating operating (without depreciation) costs are included in the current costs of the relevant periods;

- compensating investments are introduced in the accounting period and are deducted a year later;

- costs are multiplied by the reduction factor;

- integral costs for the project are calculated.

\section{Conclusions}

The scientific and methodological basis for the application of program management as an organizational form of managing the construction phase is the implementation of completed construction queues using the nodal method at critical points in the lifecycle of the multiproject, which makes it possible to identify possible options and methods for shortening construction times that become important reserves for increasing the efficiency of operation and reducing costs construction at the expense of costs in total cost of ownership of the real estate of the industrial park.

Constructed diagrams of the most important parameters of the life cycle, as well as the selected phases of the investment cycle of reproduction, are grouped into two groups, which include pre-production and production costs (phases of initial development of the projected capacity (tOS), subsequent normal operation (toe) and some periods of extinction tug) allow you to plan the order of construction (the period between investment of funds and the beginning of the receipt of an effect from them) and the periodicity of measures for the reorganization of production using active s organizational and technical tools, which makes it possible to obtain an effect with an integral evaluation of their effectiveness (effectiveness).

Analysis of modern theories of management and practice of application of rational models of development and redevelopment of industrial real estate makes it possible to determine the key factor that influences the reduction of the construction time of various types of industrial parks, namely, the factor of "continuity of management" in construction, which determines the effectiveness of managing the efficiency of construction and operation of such objects taking into account the risk factors in conjunction with the organizational and economic reliability of construction and organizational and economic sustainability of industrial development. 


\section{References}

1. A. Murzin, Real estate: economics, evaluation and development (Phoenix, Rostov on Don, 2013)

2. G. Savitskaya, Analysis of economic activity of enterprises (New knowledge, Minsk, 2004)

3. G. Sternik, S. Sternik, N. Tulinova, Real Estate Development (Prospekt, Moscow, 2016)

4. A. Yudina, Technological processes in construction (Academy, Moscow, 2013)

5. T. Altenburg, J. Meyer-Stamer, World Development, 27, 1693-1714 (1999)

6. C. Armstong, Project Portfolio Selection Methods (University of Wisconsin, Platteville, 2004)

7. S.A. Baronin, A.G. Yankov, S.A. Bizhanov, Acta Zhengzhou University Overseas Edition Life Science Journal 11 (8), 249-253 (2014)

8. M.N. Best, The New Competition Institution of Industrial Restructuring (Blackwill, Oxford, 1990)

9. R. Boyer, Problemes economic, 2653, 15-23 (2000)

10. P. Cooke, Knowledge Economies: Clusters, Learning and Cooperative Advantage (Routledge, London, 2002)

11. D. Dohse, Research Policy, 29, 11-33 (2000)

12. R. Horvdenski, C. Sadowska-Snarska, Spatial dimension of socio-economic transformation processes in Central and Eastern Europe on the turn of the 20th century, 2, 35-43 (2001)

13. J. Kitowski, Spatial dimension of socio-economic transformation processes in Central and Eastern Europe on the turn of the 20th century, 2, 28-35 (2001)

14. V. Maximov, E. Komoushenko, Mathematical Basics of Construction the Graph and Computer Models for Complicated Situations (Proceedings of the IFAC Symposium on Modelling and control of Economic systems, Klagenfurt, 2001)

15. C. Ketels, The Cluster Initiative Green Book (Christian, St Peterburg, 2003) 